\title{
Temperature-Driven Models for Insect Development and Vital Thermal Requirements
}

\author{
Petros Damos and Matilda Savopoulou-Soultani \\ Laboratory of Applied Zoology and Parasitology, Department of Plant Protection, Faculty of Agriculture, Aristotle University of \\ Thessaloniki, 54124 Thessaloniki, Greece \\ Correspondence should be addressed to Petros Damos, damos@agro.auth.gr
}

Received 15 July 2011; Revised 9 September 2011; Accepted 11 September 2011

Academic Editor: Nikos T. Papadopoulos

Copyright ( 2012 P. Damos and M. Savopoulou-Soultani. This is an open access article distributed under the Creative Commons Attribution License, which permits unrestricted use, distribution, and reproduction in any medium, provided the original work is properly cited.

\begin{abstract}
Since 1730 when Reaumut introduced the concept of heat units, many methods of calculating thermal physiological time heat have been used to simulate the phenology of poikilothermic organisms in biological and agricultural sciences. Most of these models are grounded on the concept of the "law of total effective temperatures", which abstracts the temperature responses of a particular species, in which a specific amount of thermal units should be accumulated above a temperature threshold, to complete a certain developmental event. However, the above temperature summation rule is valid within the species-specific temperature range of development and therefore several empirical linear and nonlinear regression models, including the derivation of the biophysical models as well, have been proposed to define these critical temperatures for development. Additionally, several statistical measures based on ordinary least squares instead of likelihoods, have been also proposed for parameter estimation and model comparison. Given the importance of predicting distribution of insects, for insect ecology and pest management, this article reviews representative temperature-driven models, heat accumulation systems and statistical model evaluation criteria, in an attempt to describe continuous and progressive improvement of the physiological time concept in current entomological science and to infer the ecological consequences for insect spatiotemporal arrangements.
\end{abstract}

\section{Introduction}

Climate has a profound effect on the distribution and abundance of invertebrates such as insects, and the mathematical description of the climatic influence on insect development has been of considerable interest among entomologists. Additionally, as temperature exerts great influence among the climate variables, by directly affecting insect phenology and distribution, most of the models that describe insect development are temperature driven [1-5].

This first effort for a formal description of the relation between temperature and developmental rate was taken by botanists, to model the effect of temperature on plant growth and development [6-10]. However, similar modeling procedures extended to most of the poikilothermic organisms, including insects as well [1-3]. To date, the earliest experiment that related the velocity of insect development and heat, was made by Bonnet (1779) [11] on the study of the reproduction rate of Aphis evonymi, F. [12], while the major assumption and principles that have been brought out by these earlier works, constituted the basis for all future research. Nevertheless, since then, several theoretical and experimental works have been carried out and current progress in entomology, mathematics and computation offers new means in describing the relation of temperature to insect development [13-20].

Thus, although simple predictive models have been developed during the last century, the development and broader availability of personal computers in the 70s and $80 \mathrm{~s}$ resulted in the rapid development of computer-based models to predict responses of insects in relation to climate [21,22].

Insects are adapted to particular temperature ranges and temperature is often the most detrimental environmental factor influencing their populations and distribution. In general, within optimum ranges of development and as environmental temperature decreases, their rates of development 
slow and cease at the lowest (base) temperature, while as temperature rises, developmental rates increase up to an optimum temperature, above which they again decrease and eventually cease at their temperature maximum $[4,5,15,23$, $24]$.

It is proposed that this effect of temperature on poikilothermic organism functioning is related to the effect on enzymatic activities. For instance, the conformation of enzymes is the essential step in the enzymatic reaction and this conformation depends on temperature $[22,25,26]$.

One common approach to model temperature effects on insect development is to convert the duration of development to their reciprocals. This simple transformation is used to reveal the relationship type, as it will be shown later close to linear, between temperature and rate of development and permits the determination of two vital parameters of development namely, the thermal constant $(K)$ and the base or lower temperature of development $\left(T_{\min }\right)$. The thermal constant is expressed as the number of degree-days (in ${ }^{\circ} \mathrm{C}$ ) and provides an alternative measure of the physiological time required for the completion of a process or a particular developmental event $[4,5,21,27]$.

Attempts to quantify the influence of temperature on insect development rates, growth, and fecundity have been carried out by several studies for species of economic significance $[16,27-32]$. Entomologists have strong interest on this kind of relationships, since they are prerequisite to predicting timing and phenology of insect life cycle events and to initiating management actions [33-35], while application of temperature driven models are also essential in epidemiology modeling, development of effective vector control programmes [36] and prediction of biological invasions [37, 38]. From an agronomical standpoint, empirical models are often used to predict specific population events and provide means for precisely applied control methods, reducing costs as well as insecticide use $[39,40]$. Furthermore, the determination of insect-specific vital thermal requirements provides evidence to infer on observed geographical distributions and predict future dynamics $[8,41]$.

The current review highlights the importance of the relationship between insect development and its vital thermal requirements and outlines important constraint and challenges regarded to model selection and applicability in pest management and insect ecology. Within our aims, building on preview reviews, was to provide a simple account for applied entomologists and field ecologists by avoiding complex and technical details. Furthermore, efforts are also made to present a short example of the linear model and to propose a simple three parameter non-linear equation for modeling temperature effects on insect developmental rates.

The rest of this article is structured as follows. The first section describes and explains the concept of the law of total effective temperatures and how it is related to the linear models of insect development. A paradigm of the $x$-intercept method is presented in defining lower developmental threshold for Grapholitha molesta (Lepidoptera: Gelechiidae). This threshold is vital in applying phenology models in field, and to our knowledge estimated for first time in a laboratory trial. The next section summarises the most common nonlinear regression models, including the derivation of the biophysical ones, which have been proposed by researchers in order to estimate cardinal temperatures of insect development. Additionally, among the given functions, a new 3parameter equation is proposed and its general shape is also presented. Section 3 lists principal statistics that are used for parameter estimation in regression analysis and criteria for model selection among candidate equations. Section 4 briefly outlines the major heat accumulation systems for estimating species-specific heat energy in field during the growth season. Finally, there is extensive discussion regarding constraints and challenges of the models for pest management while efforts have been made to discuss how the estimated insects vital thermal requirement are related to the species environmental adaptation and field distribution.

\section{Mathematical Models and Insect Development}

Mathematical models represent a language for formalizing the knowledge on live systems obtained after experimental observation and hypothesis testing. An empirical model, if successful, determines result and cause and can be further used to describe the behavior of the system under different conditions $[39,40,42]$.

Since temperature is considered as the most critical factor affecting insect development, numerous efforts have been made by researchers to propose models to describe such relations either in laboratory or field $[6,16,22,28,29,39$, 40, 43-45]. Moreover, several of these models have been constructed in the view to be applicable for pest management $[1,21,23,27,39,42,43,46-48]$.

The term model emphasises some qualitative and quantitative characteristics of the process, which are actually abstracted, idealized, and described mathematically rather than the system itself.

Most of these approaches are based on the empirical detection of relationships and the construction of relative models that in brief capture all information about the response variable in relation to temperature. It should be noted that the presented temperature relationships can be judged as deterministic or empirical, by the sense that they consist of descriptions in which processes are not known, but where relations are established. However, all regression procedures that are followed, for parameter estimation, are purely probabilistic.

In applied entomology, empirical approaches are often used in the construction of developmental models. In general, the procedures include the delimitation of all the factors that affect development to the most limiting one, which is further chosen (i.e., temperature), in order to reveal empirical dependence of the developmental variable upon the limiting factor. A function which describes the data with higher accuracy is plugged to this relation, and its prediction power is further evaluated by using new datasets.

2.1. The Law of Total Effective Temperatures and the Linear Model. All poikilothermic organisms are related to a speciesspecific thermal constant that corresponds to time units that 
must be accumulated to complete a particular developmental event. The above principle forms the basis for all modeling approaches that have been developed since the first introduction of the heat units concept by Reaumut on 1730 and the following initiation of the temperature summation rule $[20,49]$. This rule, which was first proposed by Candolle [6] and characterized the development of all poikilothermic species, is referred to as the law of total effective temperatures and consists of the first effort in modeling temperaturedependent developmental rates instead of developmental times $[7,31,50]$.

The model is characterized by universality, since development of all species is addressed by a thermal constant which corresponds to the accumulated degree-days that are needed to complete a particular developmental stage. This principle is further related to most other cumulative degreeday approaches.

According to the law of total effective temperatures, it is possible to estimate the emergence and number of generations for a given duration, of the organism of interest, according to the following fundamental equation:

$$
K=D\left(T-T_{0}\right),
$$

where $K$ is the species (or stage-specific) thermal constant of the poikilothermic organism, $T$ temperature, and $T_{0}$ developmental zero temperature. This thermal constant provides a measure of the physiological time required for the completion of a developmental process and is measured in degree-days $(D D)$.

One popular method of estimating the above parameters is to use a linearizing transformation of the above function by calculating the rate of development $y=1 / D$ for the day variable resulting to the following equation [44]:

$$
\frac{1}{D}=-\frac{T_{0}}{K}+\frac{1}{K} T .
$$

Equation (2) is often referred to as the linear degree-day model or as the $x$-intercept method $[24,51]$, which is simply derived after growth rate fitting to a simple linear equation and then extrapolated to zero:

$$
y=a+b T .
$$

The lower theoretical temperature threshold (i.e., base temperature) is derived from the linear function as $T_{b}=$ $-a / b$ whereas $1 /$ slope is again the average duration in degree days or thermal constant $K$.

Equation (3) simply means that the thermal constant is a product of time and the degrees of temperature above the threshold temperature.

\subsection{Lower Developmental Threshold for Grapholitha Molesta} (Lepidoptera: Gelechiidae). Figure 1, for instance, describes a typical temperature effect on the developmental time of the pupae of G. molesta as well as the respective linear relationship between temperature and developmental rate according to (3). To reveal the above relations, larvae were reared in the laboratory at the Aristotle University of Thessaloniki

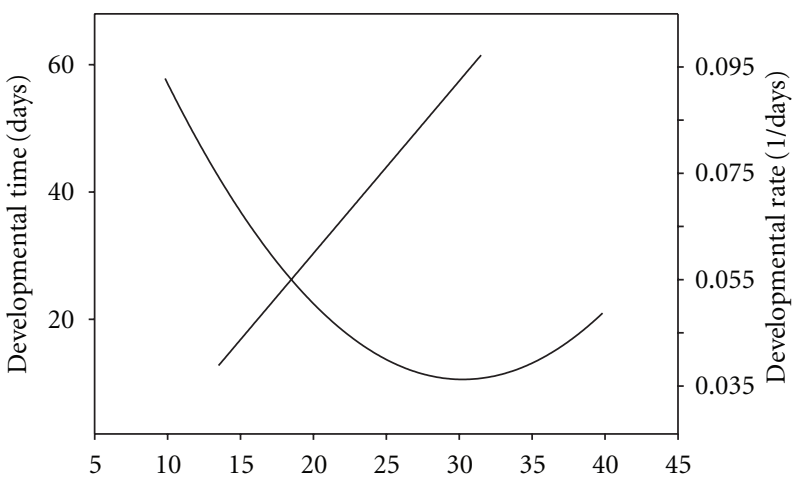

Figure 1: Typical response and temperature effect on the developmental time $\left(y=115.5-6.9 x+0.1134 x^{2}\right)$ of an insect (i.e., pupal stage of $G$. molesta) and respective linear relationship between temperature and developmental rate according to the linear model $\left(y=0.041 x-0.0412, T_{\min }=10^{\circ} \mathrm{C}\right)$.

and respective pupae were incubated at different constant temperatures at constant laboratory conditions $(15,20,25$, and $30^{\circ} \mathrm{C}$, and $65 \pm 5 \%$ R.H., $\left.16: 8 \mathrm{~h} \mathrm{~L}: \mathrm{D}\right)$.

The need for inverse regression, as also displayed in the above paradigm, arises most often when the observed variable (developmental time) is the result of the major factorial cause variable (temperature) which is not subjected to error. Thus, in order to measure the predicted variable with negligible error and avoid bias, such kind of "physical problems" should be treated as inverse even if causality is not known or not considered [21, 27, 39, 52, 53].

However, if the dependent variable is measured with negligible error (relative to error in the measurement of the factorial variable), or is much smaller than that of the response variable, the direct prediction will involve bias, unless the two variables are perfectly correlated [53]. Therefore, regressions in which both variables are subjected to error have been also proposed [12] and are applied to insect temperature-dependent development to improve prediction precision $[21,27]$ :

$$
D T=K+T_{b} D,
$$

where $D$ is development time (days) and $T$ is temperature.

One of the major advantages of this equation, as in the case of the $x$-intercept method, is simplicity and the existence of biological interpretation over the estimated parameters: thermal constant and lower temperature threshold. Its added value, however, is increased precision in parameter estimation and the detection of outliers that reside on the non linear response curve and should be eliminated by the regression [44].

2.3. Nonlinear Regression Models. Although in practice the linear models are quite adequate over a range of favourable temperatures, they proved unsecure in predicting development in extreme conditions and temperatures in which the relationship becomes non linear [21, 27, 48, 55, 57]. Hence, ideally one should know the response of the organism 


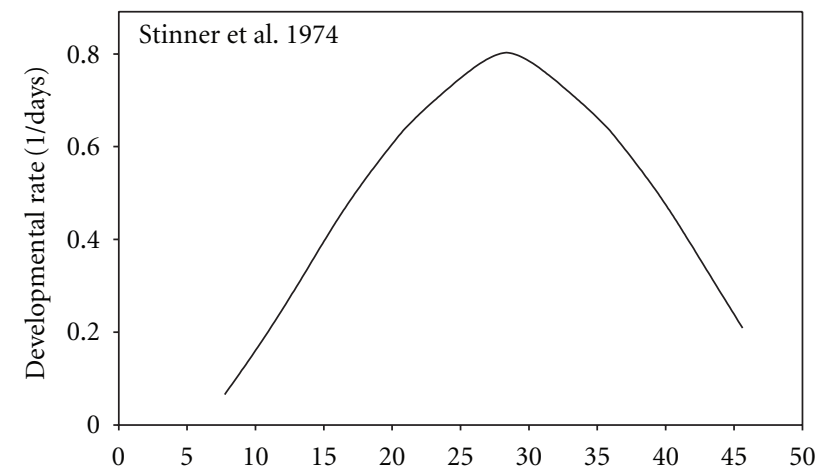

(a)

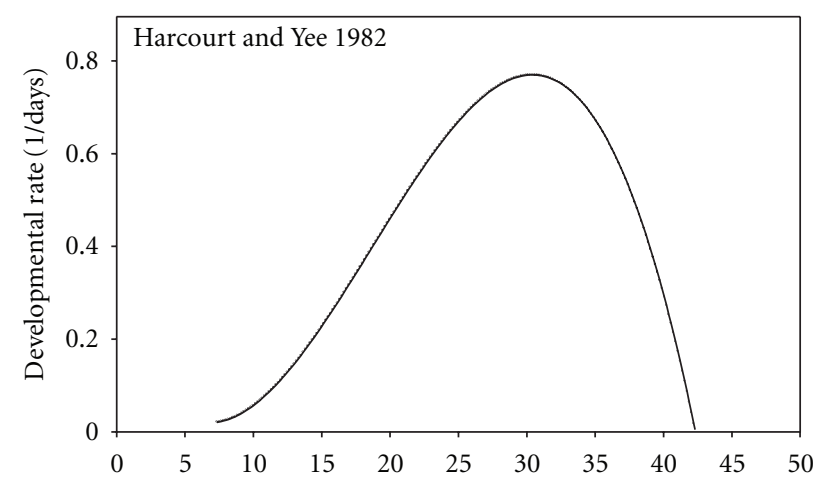

(c)

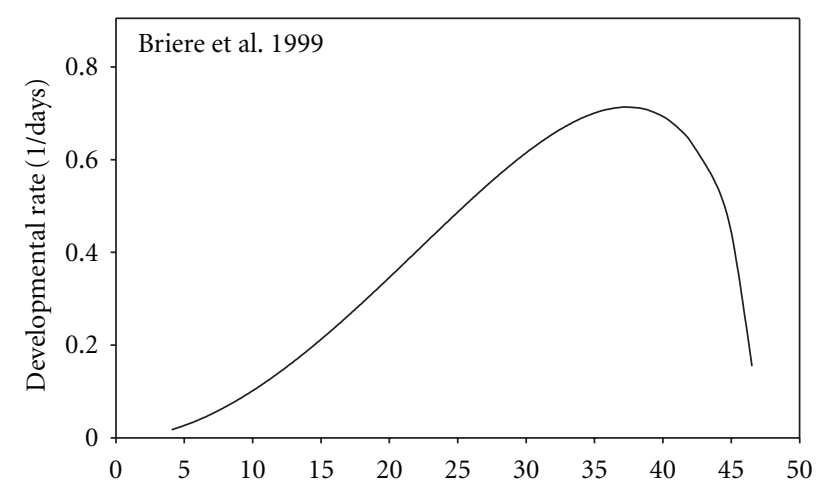

(e)

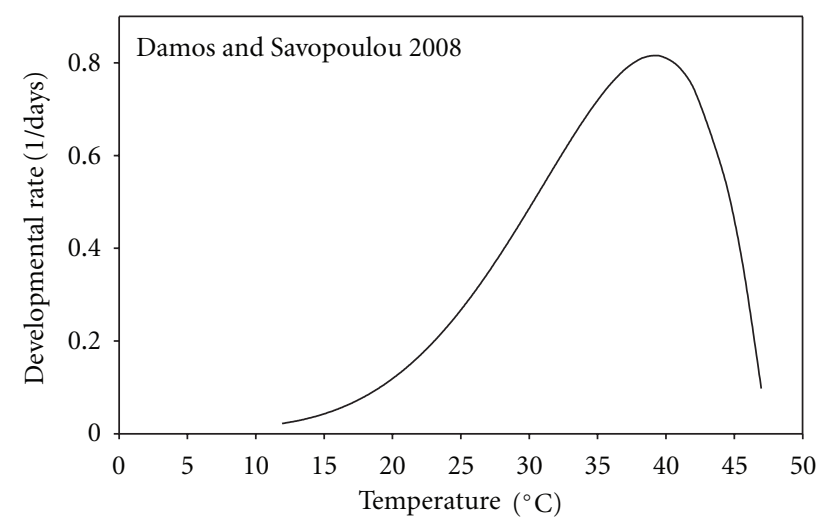

(g)

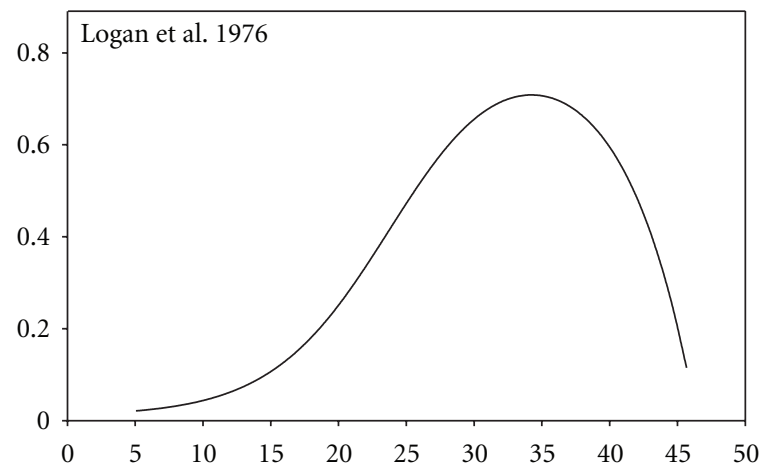

(b)

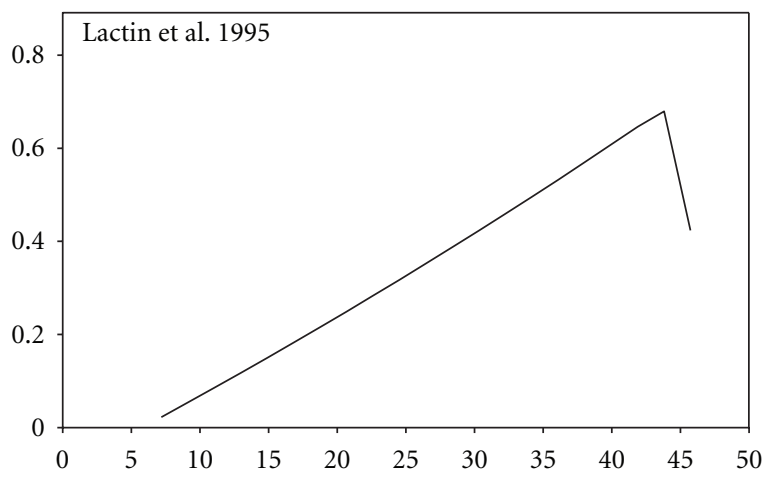

(d)

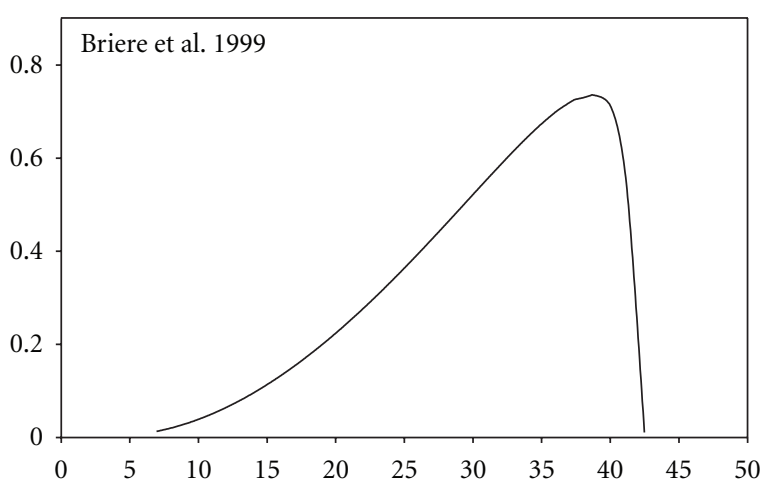

(f)

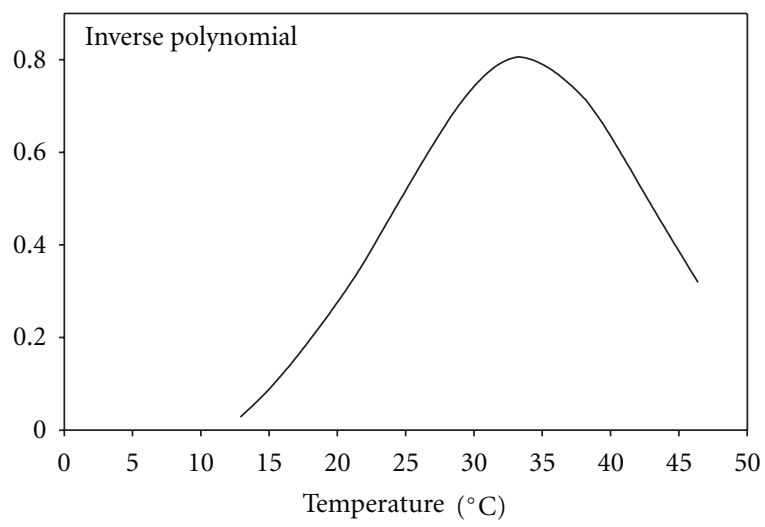

(h)

FIGURE 2: Typical relationships between temperature and insect developmental rates according to several representative non-linear models. 
TABLE 1: Some representative regression models that have been created for the description of temperature-dependent development of insects and related arthropods.

\begin{tabular}{|c|c|c|c|}
\hline Non-linear model & Equation & Description & Reference \\
\hline $\begin{array}{l}1 / D=c /\left(1+e^{(a+b \cdot T)}\right), \quad \text { if } T \leq T_{\mathrm{opt}} \\
1 / D=c /\left(1+e^{\left[\left(a+b \cdot\left(2 \cdot T_{\mathrm{opt}}-T\right)\right]\right.}\right), \quad \text { if } T>T_{\mathrm{opt}}\end{array}$ & (1) & "Stinner" (non-linear) & Stinner et al. 1974 [54] \\
\hline $1 / D=\psi \cdot\left[1 /\left(1+k \cdot e^{-\rho \cdot T}\right) \cdot e^{-\left(\left(T_{\max }-T\right) / \Delta\right)}\right]$ & (2) & "Logan 10" & Logan et al. 1976 [55] \\
\hline $1 / D=a \cdot T^{3}+b \cdot T^{2}+c \cdot T+d$ & (3) & "3rd-order polynomial" (non-linear) & Harcourt and Yee 1982 [56] \\
\hline $1 / D=e^{\rho \cdot T}-e^{\left(\rho \cdot T_{\max }-\left(T_{\max }-T / \Delta\right)\right)}+\lambda$ & (4) & "Lactin" (non-linear) & Lactin et al. 1995 [57] \\
\hline $1 / D=a \cdot T \cdot\left(T-T_{\min }\right) \cdot\left(\sqrt{T_{\max }-T}\right)$ & (5) & "Briere 1" (non-linear) & Briere et al. 1999 [29] \\
\hline $1 / D=a \cdot T \cdot\left(T-T_{\min }\right) \cdot\left(\sqrt{T_{\max }-T}\right)^{(1 / m)}$ & (6) & "Briere 2" (non-linear) & Briere et al. 1999 [29] \\
\hline $1 / D=\rho \cdot(a-T / 10) \cdot(T / 10)^{\beta}$ & (7) & "Simplified beta type" (non-linear) & $\begin{array}{l}\text { Damos and Savopoulou-Soultani } 2008 \\
\text { [27] }\end{array}$ \\
\hline $1 / D=a /\left(1+b T+c T^{2}\right)$ & (8) & "Inverse second-order polynomial 1" & This study \\
\hline
\end{tabular}

over the entire range of temperatures to compute accurately developmental rates over all temperature range.

Several non linear models have been proposed to describe developmental rate response curves over the full range of temperatures, aimed either to build general insect phenology models, or to be used as forecasting tools for pest management $[4,5,20,21,27,29,31,34,45,50,57-60]$. Although the procedure can be easily generated using several different softwares, one important limitation is that the optimization procedure is performed only for the dependent variable and assumes that the residual errors of the independent variable are negligible.

Table 1 presents some of the most common non-linear models that have been developed to describe insect development rates over the whole range of temperature. Figure 2 depicts typical temperature response curves according to some common non-linear equations that are presented in Table 1. The models have been abstracted by the respective references and are additionally generated for representative selected empirical data.

Typically, and according to all models, there is no growth below the lower temperature threshold, while developmental rate increases and reaches a maximum at optimal temperature and declines rapidly approaching zero at the higher temperature threshold that is often considered as lethal temperature.

2.4. Biophysical Models. Biophysical models predict the behavior of insect developmental rate in physical terms. Since "temperature rate biophysical models" are representations of temperature-depended development and based on the primitive rules of temperature dependence of reaction rates narrowed by biophysics, they are differentiated to all the other non-linear models.

The conformation of enzymes is the essential step in the enzymatic reaction and this conformation depends on temperature. Because poikilothermic development can be considered as a macroscopic revelation of enzyme reactions, in which temperature exerts a catalytic effect at a molecular level, these equations have been applied in modeling microorganism growth and in describing temperaturedependent development of arthropods.
Traditionally, such kinds of relations are based on the empirical equations of Van't Hoff's law [7], Arrhenius [46], and Eyring [50, 60-62]; and these relationships provided the principal foundation of later works.

Van't Hoff, based upon the experimental results of the botanist and pharmacist Pfeffer (who first measured osmotic pressure in 1877), concluded that the osmotic pressure $\pi$ of a sugar solution in relation to its volume is constant and directly related to the absolute temperature $T$ :

$$
\pi=k T \text {, }
$$

where $k$ is a constant of analogy. Furthermore, by applying the ideal gas state equation to describe the osmotic pressure, as in the case of ideal gas, results in

$$
\pi=R T \Sigma c_{i},
$$

where $R$ is the universal gas constant, $T$ is the absolute temperature, and $c_{i}$ is the molar concentration of solute $i$. Interpretation of (5) and (6) simple states that the rate of chemical reactions increases between two- and threefold for each $10^{\circ} \mathrm{C}$ rise in temperature. This conclusion, according to Van't Hoff's law, that an increase in temperature will cause an increase in the rate of an endothermic reaction had a huge impact in chemistry, biochemistry, and physiology.

The Arrhenius equation relates the chemical reaction rate constant to temperature $T$ (in Kelvins or degrees Rankin) and the activation energy of the reaction $E_{\alpha}$ as follows:

$$
k=k_{0} e^{-E_{a} / R T},
$$

where $K_{0}$ is the rate coefficient, $E_{a}$ the activation energy, $R$ the universal gas constant, and $T$ absolute temperature. According to the Eyring function [61] any biochemical reaction rate (without prior enzyme activation) increases exponentially while in the equation parameterized by Schoolfield et al. [60] the reaction rate $r(T)$ is given as a modification of a reference reaction rate to a respective reference temperature:

$$
r(T)=\rho \frac{T}{T_{\mathrm{ref}}} e^{\left[H_{\alpha} / R\left(1 / T_{\mathrm{ref}}-1 / T\right)\right]} .
$$

In (8), $\rho$ is considered as $1 /$ time (reference rate) and $H_{\alpha}$ corresponds to the temperature sensitivity coefficient 
(or activation enthalpy in $\mathrm{J} / \mathrm{mol}$ ) and $R$ is the universal gas constant $\left(8.314 \mathrm{~J} \mathrm{~K}^{-1} \mathrm{~mol}^{-1}\right)$. The above equation can be applied to any intended temperature sensitive rates including developmental rates as well.

However, when dealing with biological rates, exponential increase is observable on a limited range and not throughout all temperature regimes. Sharp and DeMichele [63] considered activation process of the two extreme temperatures as independent and proposed a modification of the Arrhenius equation. This result to an equation having two components in the denominator, each for the description of the reversible inactivation of the rate-controlling enzyme considering both low and high temperatures and including "linearity" at middle temperatures:

$$
r(T)=\left[\frac{T \cdot \exp \left[\left(\Phi-\Delta H_{A}^{\neq} / T\right) / R\right]}{1+\exp \left[\left(\Delta S_{L}-\Delta H_{L} / T\right) / R\right]+\exp \left[\left(\Delta S_{H}-\Delta H_{H} / T\right) / R\right]}\right],
$$

where $r(T)$ is the mean developmental rate at temperature $\mathrm{T}$ (1/time), $T$ is the temperature in $K, R$ is the universal gas constant $\left(1.987 \mathrm{cal} \mathrm{deg}^{-1} \mathrm{~mol}^{-1}\right)$, while the other parameters are associated with the rate-controlling enzyme reaction: $\Delta H_{A}$ is the activation enthalpy of the enzyme reaction while $\Delta H_{H}$ is the change in enthalpy associated with hightemperature inactivation of the enzyme ( $\left.\mathrm{cal} \mathrm{mol}^{-1}\right), \Delta S_{L}$ is the change in entropy associated with low-temperature inactivation of the enzyme (cal deg ${ }^{-1} \mathrm{~mol}^{-1}$ ), and $\Phi$ is a conversion factor having no thermodynamic meaning.

Figure 3 gives the biophysical model (9) for representative datasets as well as the respective Arrhenius plot. The biological interpretation of the above function has analogies to those of the Arrhenius function in which the dominator represents the fraction of rate-controlling enzyme that is in the active state. Derivation of the above mathematical function as well as the basic assumptions and modifications of the original formula are covered in details in $[60,63]$.

\section{Statistics for Parameter Estimation and Model Comparison}

3.1. Parameter Estimation. Numerous procedures have been developed for parameter estimation and inference in regression analysis.

Campbell et al., 1974 [43, 64], provide statistics for the Standard error (SE) of the lower developmental threshold $\left(T_{\min }\right)$ and the thermal constant $K$ for the linear model based on "principal-manually" derived statistics:

$$
\mathrm{SE}_{T_{\min }}=\frac{\bar{r}}{b} \sqrt{\frac{s^{2}}{N \cdot \bar{r}^{2}}+\left[\frac{\mathrm{SE}_{b}}{b}\right]^{2}}
$$

where $s^{2}$ is the residual mean square of $r, \bar{r}$ is the sample mean, and $N$ is the sample. Additionally, the size of the $\mathrm{SE}_{K}$ for the thermal constant $K$ for the linear model having slope $b$ is, respectively [64],

$$
\mathrm{SE}_{K}=\frac{\mathrm{SE}_{b}}{b^{2}}
$$

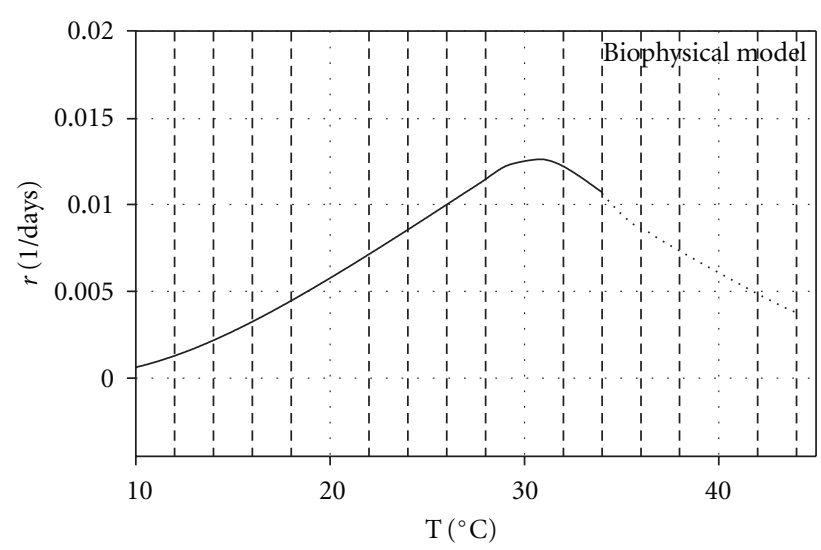

(a)

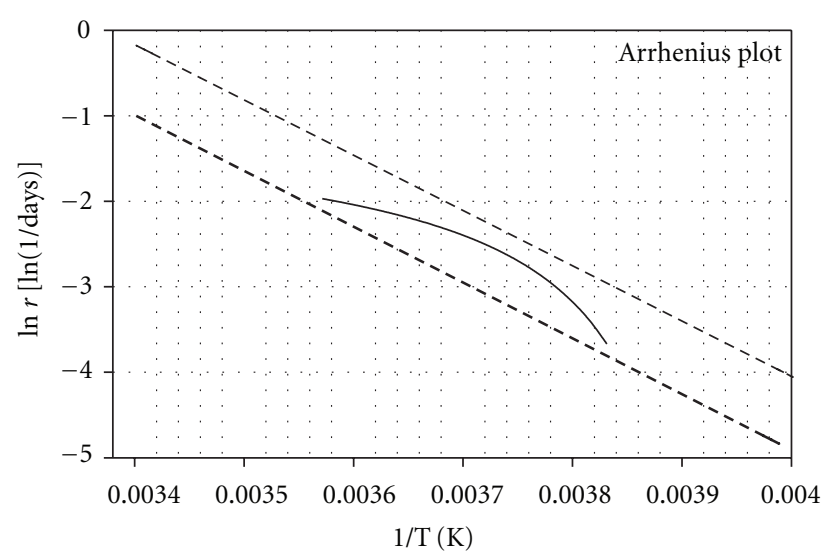

(b)

FIGURE 3: Curve shape of the biophysical model of sharp and DeMichelle [63] as modified by Schoolfield et al. [20] (a) and the respective Arrhenius plot (b).

However, several other procedures are also proposed for parameter estimation and relative statistics. The most common are the maximum likelihood (ML) and the ordinary least square (OLS) estimation, and they are used for both linear and non linear models [65].

Point and interval estimation using ML relies on distributional assumptions (here a specific probability function for error dispersion must be specified), in contrast to OLS point estimates, which generally do not require hidebound distributional assumptions, are unbiased, and have minimum variance.

The OLS minimise the sum of square residuals of the regression function of interest. Additionally, most statistical packages of parameter estimation are based on the Levenberg-Marquardt algorithm (LMA) which provides a numerical-iterative solution of curve fitting over a space of parameters of the function.

The Marquardt algorithm [66] is a least squares method based on successive iterations for parameter optimization. Thus, if $\left(x_{i}, y_{i}\right)$ is the given set of $n$ empirical observation pairs of the independent (temperature) and dependent (developmental times) variables, the algorithm optimizes the 
parameters $p$ of the model curve $f(x, p)$ so that the sum of the squares of the deviations is minimum:

$$
g(p)=\sum_{i=1}^{n}\left[y_{i}-f\left(x_{i}, p\right)\right]^{2}
$$

The method is that the analyst has to provide an initial starting guess for final parameter estimation. This is an important constrain of the method and especially in curves with multiple minima the initial guess must already to be closed to the final solution. Furthermore, problems can arise in the case of observational data (i.e., time series) in which covariates can exist between observed and response variables.

The methods described above for calculating standard error and confidence intervals for a parameter relay on the assumption that the statistic of interest is assumed to be normal distributed. Thus, there is no need whatsoever for bootstrapping in regression analysis if the OLS assumptions are met. However, in the case of estimating population values in the absence of any information (i.e., variables in which sampling distributions and variances are unknown due to limited data), or in the case in which the variable is the final result of several observations (as in the case of life table statistics), parameter estimation and standard errors can be based on resampling methods such as the Bootstrap and/or the Jackknife method, or even based on Bayesian inference estimation.

For more details on resampling the reader should consider the references cited $[67,68]$.

3.2. Model Comparison. Since several regression models are available it is convenient to provide criteria or goodness of fit tests for model comparison. For instance, a common question that applied entomologists are facing is how to compare two different models for a given species and/or how to compare two different species with a given model.

Generally, several criteria have been proposed to evaluate model performance including the root mean square error (RMSE), the Pearson $x^{2}$, the deviance $\left(G^{2}\right)$ statistics, regular and adjusted to the parameter numbers regression coefficients, and information criteria such as the Akaikes and Bayes-Schwarz information criteria $[21,27,39,69]$.

The idea behind most of these criteria is to measure the "range" of which the predicted values of a given model match the observed and can be applied in evaluating prediction capability for a particular dataset (i.e., one species-several models). Some of them are described in brief.

The Pearson $x^{2}$ statistic is based on observed $(O)$ and expected fitted or predicted (e) observations and has similarities to the Root Mean Square Error [27, 65]:

$$
x^{2}=\sum_{i=1}^{n} \frac{(o-e)^{2}}{e}=\sum_{i=1}^{n} \frac{\left(y_{i}-n \hat{\pi}_{i}\right)^{2}}{n \hat{\pi}_{i}\left(1-\hat{\pi}_{i}\right)}
$$

Where $y_{i}$ is the observed value of $Y, \hat{\pi}_{i}$ is the predicted or fitted value of $x_{i}$ and $n$ is the number of observations. Additionally, based on the same concept a "prediction capability" index $d$ can be addressed to be used to compare candidate models and rank them according to the degree to which the predictions are error-free:

$$
d=1-\frac{\left[\sum\left(P_{i}-O_{i}\right)^{2}\right]}{\sum\left[\left(\left|P_{i}-\overline{O_{i}}\right|\right)+\left(\left|O_{i}-\overline{O_{i}}\right|\right)\right]^{2}},
$$

where $\bar{O}_{i}$ is the average of the observed values $[27,70]$.

For a comparison of only two models, an efficacy ratio can be calculated as follows $[27,70]$ :

$$
E_{1,2}=\frac{\mathrm{MSE}_{1}}{\mathrm{MSE}_{2}} .
$$

Where the respective to the models efficacy ratio $E$ is based on the mean square errors (MSE) and can be used as evaluation index [70]. Values close to 1 indicating very low differences between the selected models in predicting a particular dataset $[21,27]$.

Considering that there are cases in which different datasets (i.e., two different species) are described with a particular model and cases in which there is model selection among equations that differ on the number of parameters, model performance comparisons can be made according to the adjusted coefficient of determination ( $\left.\operatorname{Adj} \cdot r^{2}\right)$ and on the Akaike's information criteria [71].

The Adj $\cdot r^{2}$ is a modification of $r^{2}$ that adjust for the number of explanatory terms in a model. Unlike $r^{2}$, Adj $\cdot r^{2}$ increases only if an additional new term improves the model more than would be expected by change $[21,39]$. The Adj $\cdot r^{2}$ is defined as

$$
\operatorname{Adj} \cdot r^{2}=1-\frac{\operatorname{RSS} /(n-(\vartheta+1))}{\mathrm{SS} /(n-1)} .
$$

Akaike's information criterion (AIC) developed and proposed by Akaike in 1974 [39] is

$$
\mathrm{AIC}=n \cdot[\ln (\mathrm{RSS})]-[n-2 \cdot(\theta+1)]-n \cdot \ln (n)
$$

and the Bayesian-Schwartz information criterion (BIC or SIC) was proposed on 1978 and is [39]

$$
\mathrm{BIC}=n \cdot[\ln (\mathrm{RSS})]+(\theta+1) \cdot \ln (n)-n \cdot \ln (n),
$$

where RSS is the residual sum of squares and SS total sum of squares, $\theta$ number of parameters and $n$ observation number. These criteria permit to infer on how the different number of parameters add to the explanatory power of the candidate model.

\section{Physiological Time and Heat Unit's Accumulation Systems}

Considering the above models in defining cardinal temperatures of development in the laboratory, as well as the respective for each stage and species thermal constants, the interest is to apply this knowledge in order to make field predictions of temperature effects on insect phenology in time and space, according to the physiological time and related heat accumulation systems [50, 72-75]. 
Often referred to also as thermal time, the progress of the development of an organism is viewed as a biological clock that measures time units. Thus, although physiological time accelerates or slows according to prevailing temperatures, the time units to complete a particular developmental event in field should be the same as defined in the laboratory and equals the species specific thermal constant.

Thus, since the law of effective temperatures suggest that the completion of a given stage in development requires an accumulation of a definite amount of heat energy, similar approaches can be followed in which effective accumulated temperatures are estimated by the respective heat energy in field during the growth season.

According to this approach the amount of age or development accumulated from time 0 to $t$, and for discrete time intervals is

$$
\Delta \alpha=\sum f[T(t)] \Delta t, \quad[T(t)]>0 .
$$

According to this function the species integrate temperature effects according to some function, $f$, peculiar to their species. This function, $f[T(t)]$, can be either linear or non-linear. If $f[T(t)]$ is assumed to be linear, then the developmental rate is proportional to temperatures above threshold (as defined according to the $x$-intercept method and apart from the linearity check of the ratetemperature curve), on the other hand, several non linear relations exist such as the logistic curve. However, in order to be effective, heat summation takes into account only the active temperatures within the species-specific range of development $[24,51]$.

Several methods have been proposed in calculating degree days accumulated in field, as well as related software. However, for the sake of brevity, in this review, the following three widely applied methods the average method, the modified average method, and the modified sine wave method, are briefly discussed.

4.1. Average Method. According to the average method developed by Baskerville and Emin [14], which is the simplest one, the number of daily degree-days is calculated by subtracting the base temperature from the average daily temperature as follows:

$$
D D=\left[\frac{\min T+\max T}{2}\right]-T_{\min } .
$$

Among the disadvantages of the above approach is that it does not take into account those daily minimum temperatures that can fall below the species lower temperature thresholds. This situation is very common in spring and results in bias and underestimation of degree-days accumulated by the insect since not all hourly temperatures during a day are above the threshold level. Thus, during this short period, development proceeds but is not taken into account by the proposed heat accumulation system.

4.2. Modified Average Method. In order to avoid the abovementioned disadvantage it is convenient to modify the first component of (20) by substituting minimum temperature with lower temperature threshold, thereby approximating closer reality by calculating the daily temperature accumulation that corresponds to the interval between maximum temperature and that which is higher than the lower threshold of the species, or

$$
D D=\left[\frac{T_{\min }+\max T}{2}\right]-T_{\min } .
$$

This approach will result in a higher number of degreedays by taking into account development during the short periods in which temperature is slightly above the lower developmental threshold.

4.3. Modified Sine Wave Method. In principle mathematical relationships for this technique were given by Baskerville and Emin [14], Allen, and Watanabe [2]. Arnold [24, 51, 76] showed that the area under the temperature curve, the amplitude of which has been adjusted to the daily maximum and minimum temperatures for a given day, can be approximated according to sine curve.

Thus, according to the modified sine wave method, proposed by Allen [51], a trigonometric sine function is being used to describe this kind of daily temperature fluctuations. Based on the same principle as previously stated, heat accumulations during a day correspond to the area above the species lower temperature threshold. It is also noteworthy to state that this method leads to similar results as the modified average method in the case where minimum temperature is higher than the base temperature.

All these methods that are briefly described are based on the principle that the specimen is accumulating climate temperatures that are limited within its thresholds. Heat units are expressed as accumulated degree-days that correspond to a 24-hours daily interval that is limited between minimum and maximum temperature range and the predetermined species-specific thresholds.

\section{Discussion}

Among the scopes of this article was the description of representative models that have been proposed to model insect temperature dependent development either in the laboratory or field. However, a tremendous amount of prior work has been done in the field of insect temperature modelling since the first defined principles and the reader should consider the work of Ludwig [18], Uvarov [49], Powsner [19], Wigglesworth [26], Laudien [25] and Wagner et al. 1984 [20] for additional information.

Nevertheless, among the purposes of this review was to popularise prior studies. Several statistical criteria for model comparison are also gathered in order to integrate and familiarise most current approaches and tools for modelling the effect of temperature on insect development. This is an essential step to be made in order to draw inference upon the species ecology, spatiotemporal arrangement, and abundance.

According to selected linear and non linear models, that are presented in brief, developmental responses can 
be summarized in terms of the three critical, or cardinal, temperatures of development. In addition, since calculation of physiological time by temperature-driven field models is related to the area summated by the chosen heataccumulation system, the definition of these temperatures is a prerequisite for accurate phenology prediction. Thus, apart from the ecological concerns, the importance of finding a mathematical/statistical model which describes and then simulates the phenology of individuals under field conditions is a prior constraint for further successful timing of pest management practices in field.

Depending on their parameters, the presented models can be judged more or less complex and several algorithms for least squares estimation have been proposed for nonlinear parameters $[66,77]$. By incorporating several more factorsparameters on the equations, the authors search to gain higher accuracy on data description. However, complexity does not assure more accuracy in all cases. Prior comparative approaches should be followed to choose among most appropriate models that are available. To put forward, since most model shapes are quite similar, comparative differences of model performances can be only indicated by detailed statistical measures [39].

Hence, not all models display the same fit behaviour when carefully observed while very few provide a detailed biological interpretation of the estimated parameters. For instance, the advantage of the models proposed by Logan and Lactin over the other equations is due to the fact that they incorporate parameters that have direct biological interpretation and this is a major asset. In addition, the models proposed by Sharpe and DeMichele [63] and Schoolfield et al. [60], based on enzyme kinetic reactions, display a radical departure from those based on empirical fits to data. Nevertheless, it is common that temperature affects not only the rate of chemical reactions, but also induces conformational changes in biological systems [49].

Moreover, one disadvantage of complexity in models is that it strongly influences parameters estimation [39]. For example, although most of the polynomial models do not have any biological interpretation, probably the most important advantage they have is that parameter estimation can be easily done [56].

One other characteristic, among the presented models, is that not all of them are able to make predictions that are matched over, the experimentally derived, observed values. Unfortunately, there are instances in which optimum and upper threshold temperature predictions are quite overestimated when compared to real data [21,27]. For instance the lower temperature threshold for G. molesta, as estimated in the current laboratory trial, slightly deviates from that estimated by prior field studies [47]. Nevertheless, differences in respect to insect stage can also exist so it is important to model all development of G. molesta for safer interpretations. Thus, a good fit for a respective model has no utility if it predicts temperature thresholds that have no biological meaning. Such false predictions can result in bias on the estimation of cardinal temperatures. In most cases overestimation of optimum and maximum temperature thresholds is the result of skewed curve, although coefficients of determination are quite high but can be the result of a good data fit on the intermediate temperature range. In other words, a good fit is not always a guarantee for biologically significant model performance and a reliable and accurate data description over all temperature range $[21,27,44]$.

On the other hand, not all models can predict lower temperature thresholds, since there is no intersection with the temperature axis, when rate of development is zero [27], while in some cases cardinal temperatures are derived graphically and not numerically. In addition, the assumption of a base temperature close to $0^{\circ} \mathrm{C}$, in the cases in which the curve approximates origin may seem unreasonable, considering that it is well accepted that lower temperature thresholds for most arthropods are well above $0^{\circ} \mathrm{C}$, usually around $6-10^{\circ} \mathrm{C}$, or higher. This is also displayed for the dataset used to model G. molesta in the current study. Thus, the most currently used non-linear temperature models describe only part of the whole picture of insect temperaturedependent development. The equation of Logan et al. [55], as modified by Lactin et al. [57], due to the constant factor that intersects with the temperature axis, as well as the equation proposed by Hilbert and Logan [16], proposes a lower threshold as well, although proved rigid in describing particular datasets [27].

The above reasons, as well as the species and stagespecific plasticity on temperature responses, give important reasons that should be taken into account to choose among several available formulas. These trends have been pointed out by several researchers and are probably the major cause that resulted to the development of plethora of non-linear models in the literature $[27,31,55-57,78,79]$.

Another important constraint is that most of these models are directly related to temperature and do not take into account other climatic variables. For insects in particular, temperature is probably the most critical abiotic factor that influences their developmental rates and their life cycles, although other factors such as photoperiod, humidity, and nutrition should not be excluded, as well as crowding or density and competition $[13,40,44]$.

Furthermore, in most cases it is virtually impossible to measure the temperature that an insect experiences in its original microenvironment. For example, most plantfeeding insects display a species-specific behavior in relation to their host (i.e., crawling inside of shoots or barks at the larval stage) while others exert some control over their body temperature through their behavior (i.e., they rest at shadowed and cool places when temperature is high) [21, 40].

Considering that the existence of alternating temperatures is more probable in reality [80], there are cases in which models displayed considerable inaccuracy in predicting insect development and phenology under field conditions $[21,39,42,44,58,81,82,82,83]$.

Hence there is no perfect model, but we rely on the available ones that best describe our datasets, under certain conditions, and even though most models are oversimplifications, they are acceptable for empirical predictions in some defined ranges and instances. 
Thus, if the model is proved reliable after seedily experimental evaluation, heat accumulations of a phenological event that occurs in field should reflect that which have been estimated by the model and thereby provide means of accurate timing of pesticides and initiation of pest management tactics. Therefore, it is not risky to claim that temperature has a prominent role in insect biology and by understanding the temperature effects on insect development we are able to describe and predict the distribution and abundance of insect species in any locality [83-85].

From an ecological standpoint, insect vital thermal requirements, as described in this article (i.e., thermal constant and temperature thresholds) provide ecologically and practically useful information $[34,66,86]$. For instance, as the thermal constant differs among genera, species or even stages, their study reveals various aspects of temperature adaptation and in particular the adaptation of each to its environment. On the other hand, species specific thermal requirements can also be used as indicators of the distribution and abundance of insect populations [32].

The effect of a climatic factor, such as temperature for instance, sets the tolerance limits for a species, and this has been acknowledged by earlier studies (i.e., Shelfold, 1913: The Law of Tolerance). Later studies $[13,87,87$, 88,88 ] discuss how the species-specific "environmental boundaries" are determined by the ultimate tolerance factor (i.e., temperature) which may further restrict geographic distribution $[8,37,41,89]$.

Moreover, is it though for species whose geographical distributions ultimately are determined by temperature, global warming should result in spatial range shift [33]. Thus, the speculations on the effects of climatic change on the spatial dynamics of insect species have been quite general and populations are expected to extend their ranges to higher latitudes and elevations [37, 38, 90-94].

However, contrasting results concerning future projecting of species distribution have been also reported [90, 95], and one cannot exclude a progressive temperature selection of individuals that are adapted to the new temperature environment and especially for species with high reproductive potential [96-98] and host alternatives. Furthermore, the rate of temperature change affects species acclimation potential which further results in different conclusions regarding the responses of the species to acclimation [38, 99] and that thermal tolerances of many organisms to be proportional to the magnitude of temperature variation they experience.

Since genetic variation and potential response to selection should be positively correlated with population size, species with restricted ranges, or smaller populations, are predicted to have reduced capacity to adapt to environmental change $[96,97,100]$. On the other hand, it is more likely that temperature alteration can affect the reproductive potential of a species (i.e., abundance) and its life cycle, since additional generations or/and outbreaks are possible during the growth season [101] when not limited by photoperiod [48].

For a particular species, there is an inverse relation between the thermal constant and the lower developmental threshold and it is suggested that this trade modifies the fitness of the species and finally influences the outcome of competition between related species and their distributions $[85,88,102-104]$. Moreover, tropical species and warmadapted species tend to have higher values on their lower temperature thresholds when compared to cold-adapted species that had greater $D D$ requirements and much lower temperature ranges $[85,88,102,104]$.

Based on such linear relationships, between thermal constants and lower temperature thresholds, for several cold-blood species, it is suggested that there is an inverse relationship between lower temperature thresholds and the thermal constant associated with latitude and/or habitat that adapts each species to its thermal environment $[85,103]$. Thermal constant and respective $D D$ requirements are also based on the particular morphology and size of the species. For example, size at maturity is a function of the rate and duration of growth, and large size at maturity implies a long generation time and a correspondingly large $D D$ requirements $[17,102,105]$.

Hence, insect thermal requirements have a strong physiological and ecological interpretation since they modify species-specific ecological strategy which is adapted to a particular thermal environment $[26,49,74,84,104,106]$.

Thus, any model which provides biologically important parameters is useful in modeling population dynamics under several temperature regime alterations. In addition, by incorporating more factors in the equations, climate-driven models have the potential to describe the general ecological behaviour, abundance, distribution, and outbreaks of insects on a regional or even global scale, with important practical applications.

Finally, future research must be carried out in the direction of insect thermal adaptation in order to assess the species reproduction potential and related evolutionary properties as they respond to short- and long-term temperature alterations. The development of more sophisticated models, such as demographic system models and ecological niche models, that incorporate species-specific vital thermal requirements as well, is also an urgent necessity to improve and complete all current models. Thus models that are based on weather and other factors can more realistically estimate the spatiotemporal population evolution and invasive potential of native and nonindigenous species in new areas.

\section{Acknowledgment}

Part of this work was supported by IKY (Greek Scholarship Foundation) through a postdoctorate scholarship awarded to P. Damos.

\section{References}

[1] R. C. Akers and D. G. Nielsen, "Predicting Agrilus anxius adult emergence by heat unit accumulation," Journal of Economic Entomology, vol. 77, pp. 1459-1463, 1984.

[2] J. C. Allen, "A modified sine wave method for calculating degree-days," Environmental Entomology, vol. 5, pp. 388-396, 1976. 
[3] P. G. Allsopp and D. G. Butler, "Estimating day-degrees from daily maximum-minimum temperatures: a comparison of techniques for a soil-dwelling insect," Agricultural and Forest Meteorology, vol. 41, no. 1-2, pp. 165-172, 1987.

[4] S. Analytis, "Über die relation zwischen biologischer entwicklung und temperatur bei phytopathogenen Pilzen," Phytopathologische Zeitschrift, vol. 90, pp. 64-76, 1977.

[5] S. Analytis, "Study on relationships between temperature and development times in phytopathogenic fungus: a mathematical model," Agricultural Research, vol. 3, pp. 5-30, 1979.

[6] A. P. Candolle, Geographique botanique, Raisonee, Paris, France, 1855.

[7] J. H. Van't Hoff, "Osmotic pressure and chemical equilibrium Nobel Lecture," December 1901.

[8] M. T. Vera, R. Rodriguez, D. F. Segura, J. L. Cladera, and R. W. Sutherst, "Potential geographical distribution of the Mediterranean fruit fly, Ceratitis capitata (Diptera: Tephritidae), with emphasis on Argentina and Australia," Environmental Entomology, vol. 31, no. 6, pp. 1009-1022, 2002.

[9] Y. Weikai and L. A. Hunt, "An equation for modelling the temperature response of plants using only the cardinal temperatures," Annals of Botany, vol. 84, no. 5, pp. 607-614, 1999.

[10] S. Yang, J. Logan, and D. L. Coffey, "Mathematical formulae for calculating the base temperature for growing degree days," Agricultural and Forest Meteorology, vol. 74, no. 1-2, pp. 61-74, 1995.

[11] A. Bonnet, "Euvres d'histoire et de philosophie. i. Traité d'insectologie. Neuchâtel," 1779.

[12] T. Ikemoto, "Intrinsic optimum temperature for development of insects and mites," Environmental Entomology, vol. 34, no. 6, pp. 1377-1387, 2005.

[13] J. H. Brown, "On the relationship beween abundance and distribution of species," American Naturalist, vol. 124, no. 2, pp. 255-279, 1984.

[14] G. L. Baskerville and P. Emin, "Rapid estimation of heat accumulation from maximum and minimum temperatures," Ecology, vol. 50, pp. 514-517, 1969.

[15] J. Davidson, "On the relationship between temperature and the rate of development of insects at constant temperatures," Journal of Animal Ecology, vol. 13, pp. 26-38, 1944.

[16] D. W. Hilbertand and J. A. Logan, "Empirical model of nymphal development for the migratory grasshopper, Melanoplus saguinipes (Orthoptera: Acrididae)," Environmental Entomology, vol. 12, pp. 1-5, 1983.

[17] E. Janisch, "The influence of temperature on the life history of insects," Transactions of the Entomological Society of London, vol. 80, pp. 137-168, 1932.

[18] D. Ludwig, "The effects of temperature on the development of an insect (Popilia japonica New-man)," Physiological Zoology, vol. 1, pp. 358-389, 1928.

[19] L. Powsner, "The effects of temperature on the durations of the developmental stages of Drosophila melanogaster," Physiological Zoology, vol. 8, pp. 474-450, 1935.

[20] T. L. Wagner, H. I. Wu, P. J. H. Sharpe, R. M. Schoolfield, and R. N. Coulson, "Modeling insect development rates: a literature review and application of a biophysical model," Annals of the Entomological Society of America, vol. 77, pp. 208225, 1984.

[21] P. Damos, Bioecology of microlepidopterous pests of peach trees and their management according to the principles of integrated fruit production, Ph.D. thesis, Aristotle University of Thessaloniki, Greece, 2009.

[22] L. G. Higley, L. P. Pedigo, and K. R. Ostlie, "DEGDAY: a program for calculating degree-days, and assumptions behind the degree-day approach," Environmental Entomology, vol. 15, pp. 999-1016, 1986.

[23] A. Arbab, D. C. Kontodimas, and M. R. Mcneill, "Modeling embryo development of Sitona discoideus Gyllenhal (Coleoptera: Curculionidae) under constant temperature," Environmental Entomology, vol. 37, no. 6, pp. 1381-1388, 2008.

[24] C. Y. Arnold, "The determination and significance of the base temperature in a linear heat unit system," Proceedings of the American Society of Horticultural Science, vol. 74, pp. 430445, 1959.

[25] H. Laudien, "Changing reaction systems," in Temperature and Life, J. C. Precht, H. Hensel, and W. Larcher, Eds., pp. 355-399, Springer, New York, NY, USA, 1973.

[26] V. B. Wigglesworth, The principles of insect physiology, Chapman and Hall, London, UK, 1972.

[27] P. T. Damos and M. Savopoulou-Soultani, "Temperaturedependent bionomics and modeling of Anarsia lineatella (Lepidoptera: Gelechiidae) in the laboratory," Journal of Economic Entomology, vol. 101, no. 5, pp. 1557-1567, 2008.

[28] M. Bieri, J. Baumgärtner, G. Bianchi, V. Delucchi, and R. von Arx, "Development and fecundity of pea aphid (Acyrtosiphon pisum Harris) as affected by constant temperatures and pea varietes," Mitteilungen der Schweizerischen Entomologischen Gesellschaft, vol. 56, pp. 163-171, 1983.

[29] J. F. Briere, P. Pracros, A. Y. Le Roux, and J. S. Pierre, "A novel rate model of temperature-dependent development for arthropods," Environmental Entomology, vol. 28, no. 1, pp. 22-29, 1999.

[30] M. E. Cammell and J. D. Knight, "Effects of climatic change on the population dynamics of crop pests," Advances in Ecological Research, vol. 22, pp. 117-162, 1992.

[31] A. Campbell, B. D. Frazer, N. Gilbert, A. P. Gutierrez, and M. Mackauer, "Temperature requirements of someaphids and their parasites," Journal of Applied Ecology, vol. 11, 1974.

[32] P. S. Messenger and N. E. Flitters, "Effect of constant temperature environments on the egg stage of three species of Hawaiian fruit flies," Annals of the Entomological Society of America, vol. 51, pp. 109-119, 1958.

[33] S. A. Estay, M. Lima, and F. A. Labra, "Predicting insect pest status under climate change scenarios: combining experimental data and population dynamics modelling," Journal of Applied Entomology, vol. 133, no. 7, pp. 491-499, 2009.

[34] H. Feng, F. Goult, Y. Huang, Y. Jiang, and K. Wu, "Modeling the population dynamics of cotton bollworm Helicoverpa armigera (Hübner) (Lepidoptera: Noctuidae) over a wide area in northern China," Ecological Modeling, vol. 221, pp. 18191830, 2010.

[35] K. P. Pruess, "Day-degree methods for pest management," Environmental Entomology, vol. 12, pp. 613-619, 1983.

[36] M. A. Oshaghi, N. M. Ravasan, E. Javadian et al., "Application of predictive degree day model for field development of sandfly vectors of visceral leishmaniasis in northwest of Iran," Journal of Vector Borne Diseases, vol. 46, no. 4, pp. 247-254, 2009.

[37] A. P. Gutierrez and L. Ponti, "Assessing the invasive potential of the Mediterraneanfruit fly in California and Italy," Biological Invasions. In press.

[38] J. H. Porter, M. L. Parry, and T. R. Carter, "The potential effects of climatic change on agricultural insect pests," Agricultural and Forest Meteorology, vol. 57, no. 1-3, pp. 221-240, 1991.

[39] P. T. Damos and M. Savopoulou-Soultani, "Development and statistical evaluation of models in forecasting moth phenology of major lepidopterous peach pest complex for 
Integrated Pest Management programs," Crop Protection, vol. 29, no. 10, pp. 1190-1199, 2010.

[40] P. Damos and M. Savopoulou-Soultani, "Microlepidoptera of economic significance in fruit production: challenges, constrains and future perspectives for inegrated pest management," in Moths: Types, Ecological Significance and Control Methods, Nova Science, 2011.

[41] M. B. Davis and C. Zabinski, "Changes in geographical range resulting from greenhouse warming: effects on biodiversity in forests," in Global Warming and Biological Diversity, R. L. Peters and T. E. Lovejoy, Eds., pp. 297-308, Yale University Press, New Haven, Conn, USA, 1992.

[42] P. Damos and M. Savopoulou-Soultani, "Population dynamics of Anarsia lineatella in relation to crop damage and the development of economic injury levels," Journal of Applied Entomology, vol. 134, no. 2, pp. 105-115, 2010.

[43] A. Campbell and M. Mackauer, "Thermal constants for development of the pea aphid (Homoptera: Aphidiidae) and some of ts parasites," Canadian Entomologist, vol. 107, pp. 419-423, 1975.

[44] P. Damos, A. Rigas, and M. Savopoulou-Soultani, "Application of Markov chains and Brownian motion models in insect ecology," in Brownian Motion: Theory, Modelling and Applications, R. C. Earnshaw and E. M. Riley, Eds., Nova Science Publishers, 2011.

[45] S. Hartley and P. J. Lester, "Temperature-dependent development of the Argentine ant, Linepithema humile (Mayr) (Hymenoptera: Formicidae): a degree-day model with implications for range limits in New Zealand," New Zeeland Entomologist, vol. 26, pp. 91-100, 2003.

[46] S. Arrhenius, "Über die Reactionsgeschwindigkeit bei der Inversion von Rohrzucker durch Sauren," Zeitschrift für Physikalische Chemie, vol. 4, pp. 226-692, 1889.

[47] B. A. Croft, M. F. Michels, and R. E. Rice, "Validation of a PETE timing model for the oriental fruit moth in Michigan and central California (Lepidoptera: Olethreutidae)," Great Lakes Entomologist, vol. 13, pp. 211-217, 1980.

[48] P. T. Damos and M. Savopoulou-Soultani, "Synchronized diapause termination of the peach twig borer Anarsia lineatella (Lepidoptera: Gelechiidae): Brownian motion with drift?" Physiological Entomology, vol. 35, no. 1, pp. 64-75, 2010.

[49] B. P. Uvarov, "Insect and climate," Transactions of the Royal Entomological Society, London, vol. 79, pp. 1-247, 1933.

[50] T. L. Wagner, R. L. Olson, and J. L. Willers, "Modeling arthropod development time," Journal of Agricultural Entomology, vol. 8, pp. 251-270, 1991.

[51] C. Y. Arnold, "Maximum-minimum temperatures as a basic for computing heat units," Proceedings of the American Society for Horticultural Science, vol. 76, pp. 682-692, 1960.

[52] P. Dagnélie, Théorie et méthodes statistiques: applications agronomiques, Les Presses Agronomiques de Gembloux, Belgique, 1973.

[53] J. L. Gill, "Biases in regression when prediction is inverse to causation," Journal of Animal Science, vol. 67, pp. 594-600, 1987.

[54] R. E. Stinner, A. P. Gutierez, and G. D. Butler Jr., "An algorithm for temperature-dependent growth rate simulation," Canadian Entomologist, vol. 106, pp. 519-524, 1974.

[55] J. A. Logan, D. J. Wollkind, S. C. Hoyt, and L. K. Tanigoshi, "An analytical model for description of temperature dependent rate phenomena in arthropods," Environmental Entomology, vol. 5, pp. 1133-1140, 1976.
[56] D. C. Harcourt and J. M. Yee, "Polynomial algorithm for predicting the duration of insect life stages," Environmental Entomology, vol. 11, pp. 581-584, 1982.

[57] D. J. Lactin, N. J. Holliday, D. L. Johnson, and R. Craigen, "Improved rate model of temperature-dependent development by arthropods," Environmental Entomology, vol. 24, no. 1, pp. 68-75, 1995.

[58] W. C. Cool, "Some effects of alternating temperatures on the growth and metabolism of cutworm larvae," Journal of Economic Entomology, vol. 20, pp. 769-782, 1927.

[59] D. J. Lactin and D. L. Johnson, “Temperature-dependent feeding rates of Melanoplus sanguinipes nymphs (Orthoptera: Acrididae) in laboratory trials," Environmental Entomology, vol. 24, no. 5, pp. 1291-1296, 1995.

[60] R. M. Schoolfield, P. J. H. Sharpe, and C. E. Magnuson, "Nonlinear regression of biological temperature-dependent rate models based on absolute reaction-rate theory," Journal of Theoretical Biology, vol. 88, no. 4, pp. 719-731, 1981.

[61] T. M. Van der Have, Slaves to the Eyring equation?: Temperature dependence of life-history characters in developing ectotherms, Ph.D. thesis, Department of Environmental Sciences, Resource Ecology Group, Wageningen University, The Netherlands, 2008.

[62] X. Yin, M. J. Kropff, G. McLaren, and R. M. Visperas, "A nonlinear model for crop development as a function of temperature," Agricultural and Forest Meteorology, vol. 77, no. 1-2, pp. 1-16, 1995.

[63] P. J. H. Sharpe and D. W. DeMichele, "Reaction kinetics of poikilotherm development," Journal of Theoretical Biology, vol. 64, no. 4, pp. 649-670, 1977.

[64] A. Campbell, B. D. Frazer, N. Gilbert, A. P. Guutierrez, and M. Mackauer, "Temperature requirements of some aphids and their parasites," Journal of Applied Ecology, vol. 11, pp. 431-438, 1974.

[65] V. Barnett, Comperative Statistical Inference, Willey, NewYork, NY, USA, 3rd edition, 1999.

[66] D. V. Marquardt, "An algorithm for least squares estimation of nonlinear parameters," Journal of the Society for Industrial and Applied Mathematics, vol. 11, pp. 431-441, 1963.

[67] P. A. Eliopoulos, "Life tables of Venturia canescens (Gravenhorst) (Hymenoptera: Ichneumonidae) parasitizing Ephestia kuehniella Zeller (Lepidoptera : Pyralidae)," Journal of Economic Entomology, vol. 99, pp. 237-243, 2006.

[68] B. Effron, The Jack-Knife, The Bootsrap and Other Resampling Methods, CBMS-NSF Monograph 38, Society of Industrial and Applied Mathematics, Philadelphia, Pa, USA, 1982.

[69] H. Ranjbar Aghdam, Y. Fathipour, and D. C. Kontodimas, "Evaluation of non-linear models to describe development and fertility of codling moth (Lepidoptera: Tortricidae) at constant temperatures," Entomologia Hellenica, vol. 20, pp. 3-16, 2011.

[70] C. J. Willmot, "Some coments on the evaluation of model performance," Bulletin of American Meterorological Society, vol. 63, pp. 1309-1313, 1982.

[71] B. Zahiri, Y. Fathipour, M. Khanjani, S. Moharramipour, and M. P. Zalucki, "Preimaginal development response to constant temperatures in hypera postica (Coleoptera: Curculionidae) : picking the best model," Environmental Entomology, vol. 39, no. 1, pp. 177-189, 2010.

[72] V. I. Pajunen, "The use of physiological time in the analysis of insect stage-frequency data," Oikos, vol. 40, no. 2, pp. 161$165,1983$. 
[73] P. J. H. Sharpe, G. L. Curry, D. W. DeMichele, and C. L. Cole, "Distribution model of organism development times," Journal of Theoretical Biology, vol. 66, no. 1, pp. 21-38, 1977.

[74] F. Taylor, "Ecology and evolution of physiological time in insects," The American Naturalist, vol. 117, pp. 1-23, 1979.

[75] F. Taylor, "Sensitivity of physiological time in arthropods to variation of its parameters," Environmental Entomology, vol. 11, pp. 573-577, 1982.

[76] C. Y. Arnold, "Maximum-minimum temperatures as a basis for computing heat units," Proceedings of the American Society of Horticultural Science, vol. 74, pp. 682-692, 1960.

[77] J. Aldrich, "Doing least squares: perspectives from Gauss and Yule," International Statistical Review, vol. 66, no. 1, pp. 61$81,1998$.

[78] D. C. Kontodimas, P. A. Eliopoulos, G. J. Stathas, and L. P. Economou, "Comparative temperature-dependent development of Nephus includens (Kirsch) and Nephus bisignatus (Boheman) (Coleoptera: Coccinellidae) preying on Planococcus citri (Risso) (Homoptera: Pseudococcidae): evaluation of a linear and various nonlinear models using specific criteria," Environmental Entomology, vol. 33, no. 1, pp. 1-11, 2004.

[79] J. Y. Wang, "A critique of the heat unit approach to plant response studies," Ecology, vol. 41, no. 4, pp. 785-790, 1960.

[80] S. P. Worner, "Performance of phenological models under variable temperature regimes: consequences of the Kaufmann or rate summation effect," Environmental Entomology, vol. 21, no. 4, pp. 689-699, 1992.

[81] J. Bernal and D. Gonzalez, "Experimental assessment of a degree-day model for predicting the development of parasites in the field," Journal of Applied Entomology, vol. 116, no. 5, pp. 459-466, 1993.

[82] B. S. Nietschke, R. D. Magarey, D. M. Borchert, D. D. Calvin, and E. Jones, "A developmental database to support insect phenology models," Crop Protection, vol. 26, no. 9, pp. 14441448, 2007.

[83] L. T. Wilson and W. W. Barnett, "Degree-days: an aid in crop and pest management," California Agriculture, vol. 37, pp. 47, 1983.

[84] W. G. Wellington, "The synoptic approach to studies of insects and climates," Annual Review of Entomology, vol. 2, pp. 143-162, 1957.

[85] D. L. Trudgill, A. Honek, D. Li, and N. M. Van Straalen, "Thermal time-concepts and utility," Annals of Applied Biology, vol. 146, no. 1, pp. 1-14, 2005.

[86] P. H. Crowley, "Resampling methods for computationintensive data analysis in ecology and evolution," Annual Review of Ecology and Systematics, vol. 23, no. 1, pp. 405-447, 1992.

[87] G. Caughley, D. Grice, R. Barker, and B. Brown, "The edge of the range," Journal of Animal Ecology, vol. 57, no. 3, pp. 771-785, 1988.

[88] A. A. Hoffmann and M. W. Blows, "Species borders: ecological and evolutionary perspectives," Trends in Ecology and Evolution, vol. 9, no. 6, pp. 223-227, 1994.

[89] P. S. Messenger, "Bioclimatic studies with insects," Annual Review of Entomology, vol. 4, pp. 183-206, 1959.

[90] J. Régnière and V. Nealis, "Modelling seasonality of gypsy moth, Lymantria dispar (Lepidoptera: Lymantriidae), to evaluate probability of its persistence in novel environments," Canadian Entomologist, vol. 134, no. 6, pp. 805-824, 2002.

[91] S. H. Schneider, "Scenarios of global warming," in Biotic Interactions and Global Change, P. M. Kareiva, J. G. Kingslver, and R. B. Huey, Eds., pp. 9-23, Sinauer Associates, Sunderland, Mass, USA, 1993.
[92] V. E. Shelford, Animal Communities in Temperate America, University Chicago Press, Chicago, Ill, USA, 1913.

[93] R. W. Sutherst, "Pest risk analysis and the greenhouse effect," Review of Agricultural Entomology, vol. 79, pp. 1177-1187, 1991.

[94] S. P. Worner, "Ecoclimatic assessment of potential establishment of exotic pests," Journal of Economic Entomology, vol. 81, pp. 973-983, 1988.

[95] D. R. Mille, T. K. Mo, and W. E. Wallner, "Influence of climate on gypsy moth defoliation in southern New England," Environmental Entomology, vol. 18, pp. 646-650, 1989.

[96] S. L. Chown and J. S. Terblanche, "Physiological diversity in insects: ecological and evolutionary contexts," Advances in Insect Physiology, vol. 33, pp. 50-152, 2006.

[97] S. L. Chown, K. R. Jumbam, J. G. Sørensen, and J. S. Terblanche, "Phenotypic variance, plasticity and heritability estimates of critical thermal limits depend on methodological context," Functional Ecology, vol. 23, no. 1, pp. 133-140, 2009.

[98] D. W. Whitman, "Acclimation," in Phenotypic Plasticity of Insects. Mechanisms and Consequences, D. W. Whitman and T. N. Ananthakrishnan, Eds., pp. 675-739, Science Publishers, Enfield, NH, USA, 2009.

[99] C. Nyamukondiwa and J. S. Terblanche, "Within-generation variation of critical thermal limits in adult Mediterranean and Natal fruit flies Ceratitis capitata and Ceratitis rosa: thermal history affects short-term responses to temperature," Physiological Entomology, vol. 35, no. 3, pp. 255-264, 2010.

[100] N. Gilbert, A. P. Gutierrez, B. D. Frazer, and R. E. Jones, Ecological Relationships, W. H. Freeman and Co., Reading, UK, 1976.

[101] W. D. Williams and A. M. Liebhold, "Herbivorous insects and global change: potential changes in the spatial distribution of forest defoliator outbreaks," Journal of Biogeography, vol. 22, no. 4-5, pp. 665-671, 2009.

[102] A. Honěk, "Geographical variation in thermal requirements for insect development," European Journal of Entomology, vol. 93, no. 3, pp. 303-312, 1996.

[103] T. Ikemoto, "Possible existence of a common temperature and a common duration of development among members of a taxonomic group of arthropods that underwent speciational adaptation to temperature," Applied Entomology and Zoology, vol. 38, no. 4, pp. 487-492, 2003.

[104] D. L. Trudgill, "Why do tropical poikilothermic organisms tend to have higher threshold temperatures for development than temperate ones?" Functional Ecology, vol. 9, no. 1, pp. 136-137, 1995.

[105] A. Honěk and F. Kocourek, "Thermal requirements for development of aphidophagous Coccinellidae (Coleoptera), Chrysopidae, Hemerobiidae (Neuroptera), and Syrphidae (Diptera): some general trends," Oecologia, vol. 76, no. 3, pp. 455-460, 1988.

[106] T. M. Van Der Have and G. De Jong, "Adult size in ectotherms: temperature effects on growth and differentiation," Journal of Theoretical Biology, vol. 183, no. 3, pp. 329340, 1996. 

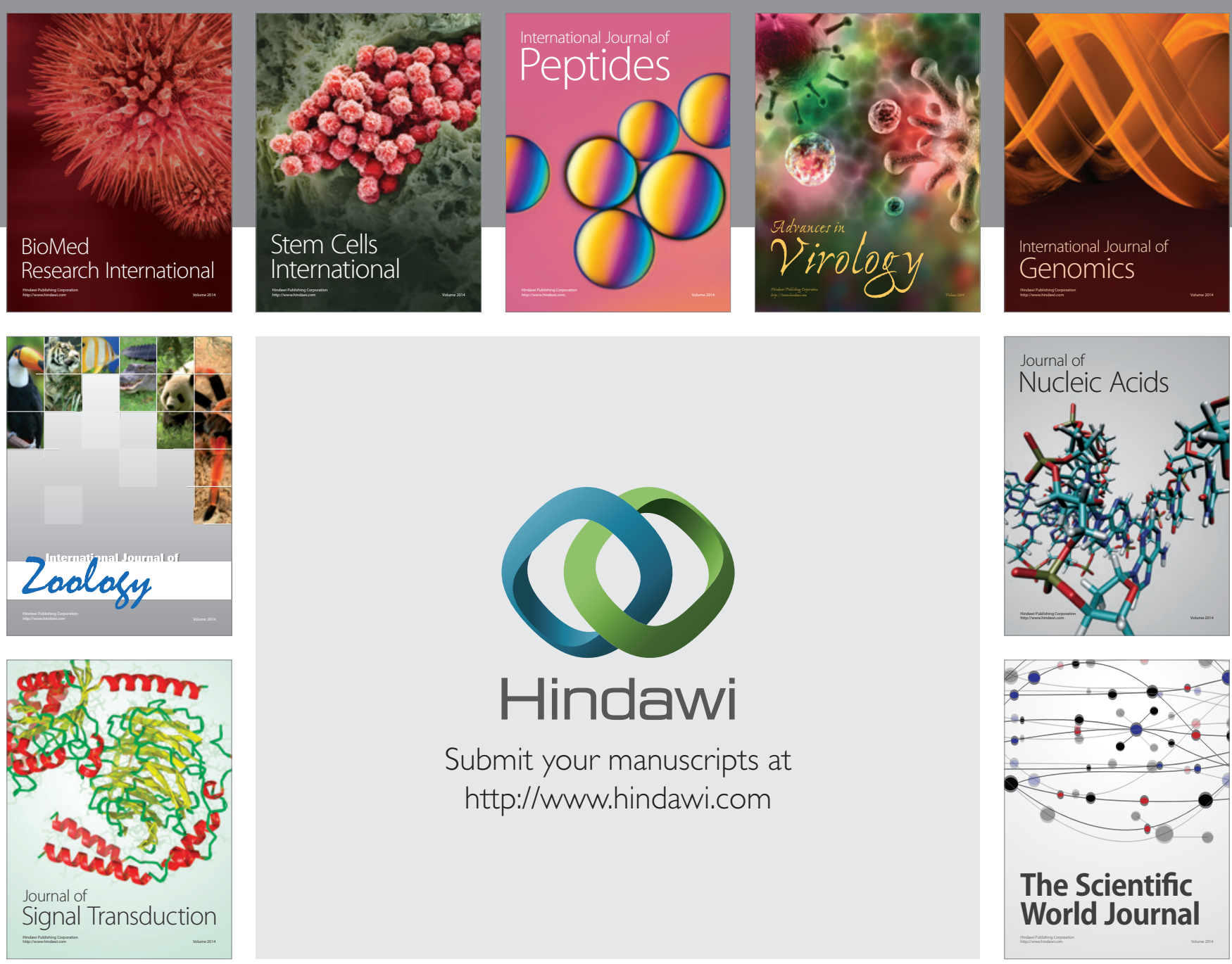

Submit your manuscripts at

http://www.hindawi.com
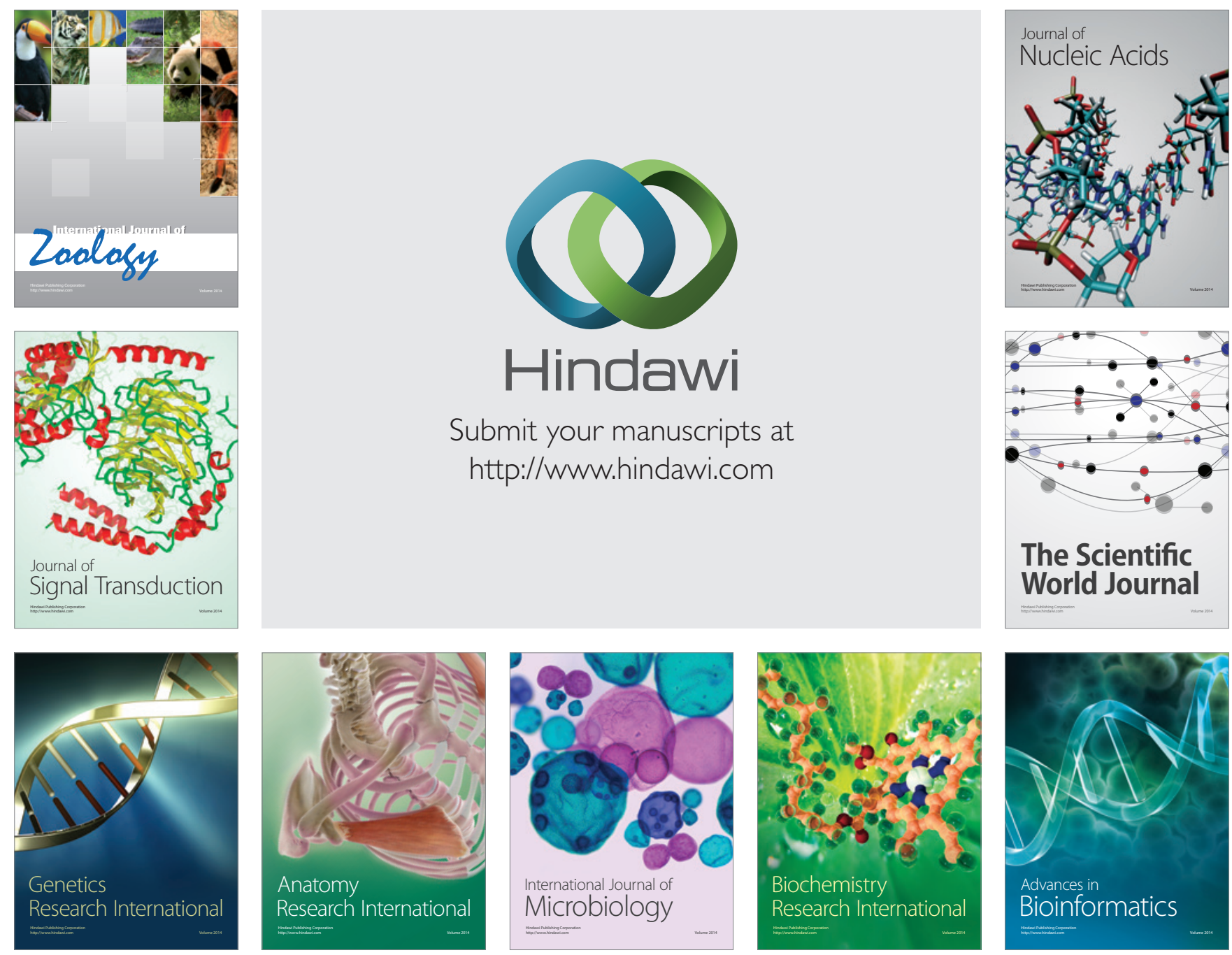

The Scientific World Journal
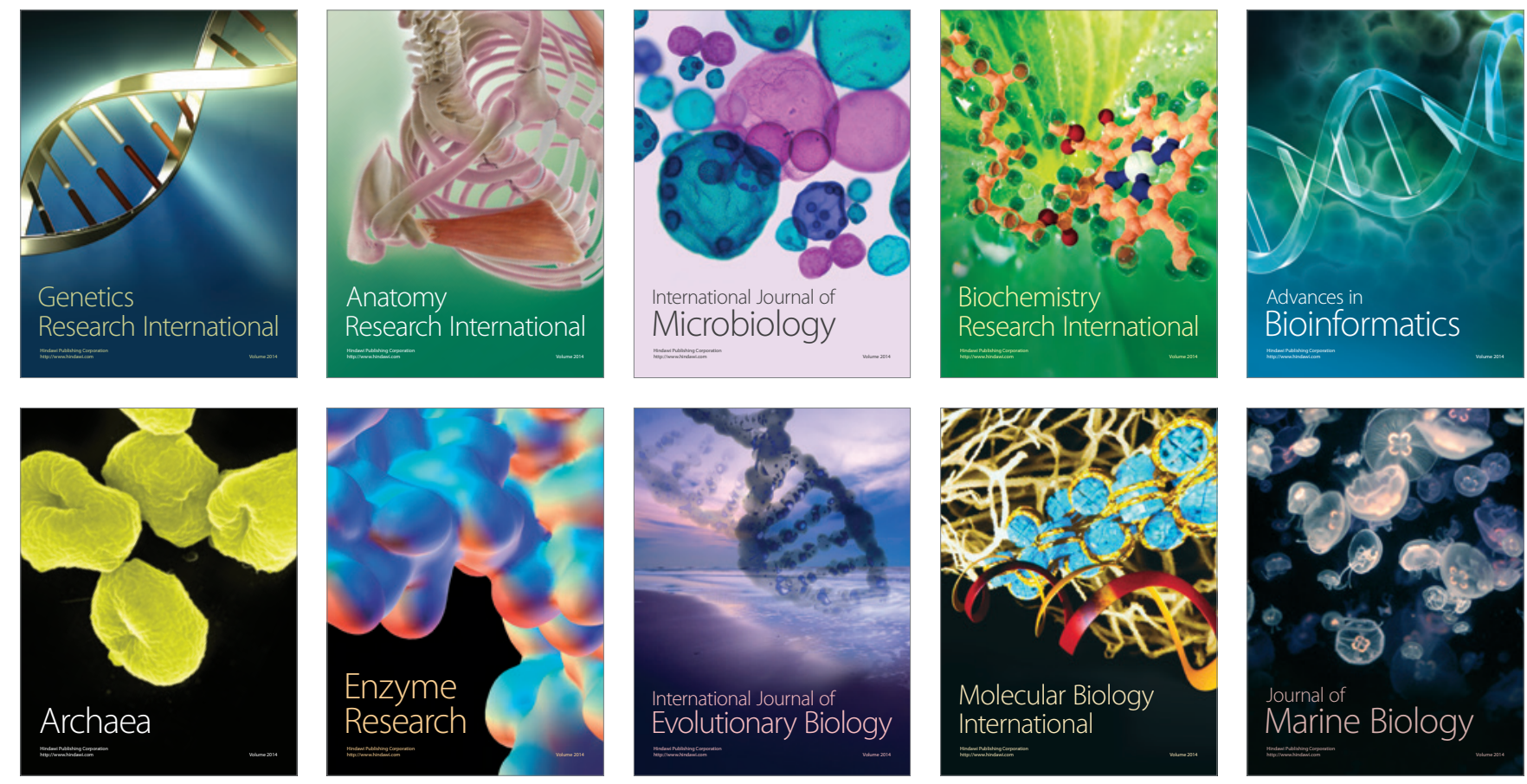